\title{
THE REACTIONS OF RANATRA TO LIGHT.
}

\author{
By S. J. Hor.mes.
}

Contributions from the Zoological Laboratory of the University of Wichigan, No. roo.

Wuth Six Figures in the 'lext.

\section{CONTENTS.}

I. INTRODLCTION.

II. Gentral habits.

III. Reactions to Light.

1-General features of the phototactic response.

2 - The negative reaction.

3-Head and swaying movements in negative phototaxis.

4-The effect of contact on phototaxis.

5-The effect of temperature on phototaxis.

6-Phototaxis leading to fatal results.

7-Inhibition of phototaxis by other activities.

8-The effect of hemisecting the brain.

9-The effect of covering the anterior half of the eyes.

Io-The effect of covering the posterior half of the eyes.

II-The effect of destroying or covering one eye.

12-Reactions of specimens with only a small part of the lateral surface of one eye exposed.

13-Phototaxis as modified by experience and habit.

14-Formation of habits of turning.

IV. General Considerations on the Phototactic Response.

\section{Introdtction.}

In endeavoring to ascertain the way in which animals of various kinds orient themselves to the rays of light I have experimented with quite a large number of species in the hope of finding forms in which the exact mode of response would reveal itself. Animals vary greatly as regards both the definiteness of their reactions to light and the ease with which their movements can be followed. Among creatures of small size such as the Copepoda, Cladocera and Ostracoda, it is almost impossible 
to observe the precise movements concerned in orientation, and in many larger forms the rapidity, irregularity, or indefiniteness of their light reactions renders the same difficulty almost equally great. In studying the reactions of animals to light we are naturally confronted with the question as to how far the movements involved are the result of choice, or something analogous thereto, and how far they may be explained as the result of reflex responses to photic stimuli. If they mainly fall into the latter category we are led to inquire just what these reflexes are and how they produce the particular kind of behavior observed.

It is a quite commonly accepted hypothesis that the phototactic reactions of organisms are effected by the action of light directly or indirectly upon the tension of muscles concerned in locomotion. In nearly all insects and in a large proportion of other arthropods this tension, if it exists, must be brought about through the central nervous system, since the opacity of the integument prevents any appreciable direct effect of light upon the musculature. In most arthropods phototactic impulses are set up by means of light entering the eyes, and not as in many lower forms through the stimulation of the integumental nerves; this is shown by the fact that when the eyes are blackened over or destroyed responses to light no longer occur. In most animals it is not possible to observe any effect of light upon muscular tension, although there is considerable indirect evidence that such an effect is produced. As RADL ${ }^{1}$ has remarked, it is difficult to explain the fact that an insect with one eye blackened over moves about in a circle except on the assumption that light affects unequally the tension of the muscles on the two sides of the body. Such circus movements are comparable to those which take place in a vertebrate animal upon the destruction of the semicircular canals in one side of the head. After this operation there is produced a marked difference in the muscular tonus of the two sides of the body and, as a consequence, the animal, instead of going in a normal manner

${ }^{1}$ Untersuchungen über den Phototropismus der Tiere, 1903. 
veers continually toward the weaker side. A small difference in the muscular tension of the two sides of an insect body which would be sufficient to cause the creature to orient itself to the rays of light might not be patent to direct observation, especially if the movements are rapid or irregular, as they frequently are. There are several forms, however, in which the effect of light upon the muscular tone is quite clearly manifested, but none more so than in the common water scorpion, Ranatra fus$c a$. In many ways this species is admirably adapted for the study of phototaxis; it is of large size, its long slender legs move in a slow and deliberate manner so that one can observe just how each action is performed; it may be readily kept for a long time in the laboratory, shows no signs of fear when being experimented with, and reacts to light with a remarkable degree of precision. For an investigation of the modus operandi of the phototactic response Ranatra is probably not equalled by any other known form.

It is especially advantageous to study phototaxis in some such organism if we wish to ascertain how far the reflex theory of orientation will carry us. If orientation is the result of comparatively direct reflexes we are better able to determine their precise mode of action. If a more involved type of reaction occurs there is a better opportunity afforded for proving its existence, and, perhaps, ascertaining something of its nature. It does not follow that because we can construct a theory to account for orientation by means of direct reflexes that the process nccessarily takes place in so simple a manner. Between the stimulus and the reaction there may be processes of a complicated nature whose existence is not ordinarily betrayed by any outward and visible sign. No one would consider a dog's following the scent of a rabbit a matter of simple chemotaxis. While it is not a process requiring conscious ratiocination, it is doubtless one involving psychic operation of considerable complexity. The possibility should be borne in mind that many of the tropisms of insects may be less simple and direct reactions than is commonly supposed. If a bee finds its way to its hive over miles of woods and fields guided by its memories of 


\section{Journal of Comparative Neurology and Psychology.}

the various objects that come into its field of vision, it is certainly something more than a mere reflex machine. In organisms which are capable of a higher type of response we should at least be on our guard in attempting to explain their tropisms as due entirely to direct reflexes involuntarily performed in response to outer stimuli. The conduct of higher animals is guided in large measure by their likes and dislikes, however we may interpret this kind of behavior in physiological terms. Between such behavior and those tropisms which are the result of comparatively simple reflexes there are, no doubt, numerous intermediate kinds of conduct. It is not unreasonable to suppose that tropisms which in low forms are brought about by direct reflexes may in higher animals complicate into reactions of the pleasure-pain type while still preserving outwardly the appearance of a more mechanical mode of response. At the same time an element of direct reflex action may be retained, although closely associated with and capable of being modified by more complicated neural processes. A consideration of the experiments described in this paper will lead us, I think, to some such view.

\section{Generdi Habits.}

Ranatras are generally found in ponds or streams among masses of vegetation where they lie quiet the greater part of the time. Although capable under certain conditions of manifesting considerable activity, these insects are usually sluggish in their movements. Their choice of habitat is probably determined, in great part at least, by their positive thigmotaxis, since they tend to insinuate themselves between objects which afford considerable contact stimuli. Their habit of coming together to form groups is a manifestation of the same tendency. When several individuals are placed in an aquarium they mass together when at rest to form a cluster in which they are often so closely aggregated and so tangled together that those which are near the center of the group experience much diffculty in disengaging themselves. In this way they may lie for hours in an almost motionless state. 
The general form and dull coloration of Ranatra tend to make it inconspicuous in its natural habitat, especially as it does not reveal its presence by its movements. When lying in the water the long breathing tube through which air is admitted to the body rests at the surface. The two parts of which it is composed occasionally approach and recede from each other, moving the air between them to and fro, an operation which doubtless assists in respiration. Air is prevented from escaping when the valves are separated, by the rows of hairs which line the margins of the concave inner faces of these structures.

Ranatra is carnivorous in habit, seizing its prey with its anterior raptorial limbs and holding it until it has sucked out its juices. It is quite destructive of fish eggs and frequently attacks and sucks the blood from young fishes. It is also reported to prey upon young tadpoles. DE LA TORRE BUEno' describes the method Ranatra employs in capturing prey as follows: "When a fly attracts its attention Ranatra very slowly, almost imperceptibly, moves its fore legs, with the knife-like tarsus away from the tibia, towards its prey. When the tibiae are almost, or quite, touching the victim the movement is so sudden and quick that one is aware of it only by seeing the prey seized. Sometimes its hold is not satisfactory, and then it will let go with one tarsus, get a firmer grip with that, and then do the same with the other. Once it has the fly securely held, Ranatra slowly approaches it to its extended beak, with which it seems to touch and feel until it finds a suitable spot, and proceeds to a leisurely meal." I have usually fed Ranatras during the winter on Notonectas, or back-swimmers, as these insects were easily obtained during this time of year. The Ranatras did not pursue the back-swimmers, but as soon as their attention was attracted to the prey they lay quietly in readiness for them with their anterior limbs prepared to quickly seize the small insects should they swim sufficiently near. If a Notonecta strikes against a Ranatra the latter makes a quick

Notes on the Stridulation and Habits of Ranatra fusca Pal. B., Canadian Entomologist, Vol. 35, p. 235, r9.93. 


\section{3 so Journal of Comparative Neurology and Psychology.}

grab for it, and, if successful in seizing it, proceeds to suck out its blood in the manner described by DE LA TORRo Bueno.

In locomotion, either by swimming or walking, the anterior limbs do not usually play a part; they are held straight in front of the body and are employed only ocrasionally to aid in changing the direction of locomotion or to clamber over some obstruction. Out of the water Ranatra walks rather awkwardly. Its long slender second and third pairs of legs are articulated close together near the center of the body and the insect is frequently tilted over so that one extremity or the other strikes against the surface over which it walks. While Ranatra is capable of flight, it rarely if ever flies to lights at night as many other aquatic hemiptera do; I have never seen any specimen around electric lights where other insects are found in abundance.

Ranatras pass the winter in the adult state. I have collected numerous specimens in a small stream north of Ann Arbor late in November, but on visiting the same locality during a thaw in January following, although a diligent search was made in their favorite habitat among aquatic plants and by digging in the mud in the sides and bottom of the stream, I did not obtain a single specimen, although Zaithas and water boatmen were found to be quite common. Possibly the Ranatras burrowed more deeply than I could dig with the apparatus employed, although the general form of the animal renders this supposition improbable. Egg laying occurs in the spring. The eggs are long and narrow and furnished at one end with a pair of filamentous processes which, according to KoRSCHELT, have a respiratory function. In ovoposition the female inserts the eggs into the stems of aquatic plants, or even into wood, the filaments projecting from the exposed ends.

Ranatras make a feeble sound by rubbing the bases of the anterior legs against the lateral processes of the prothorax. When a Ranatra is picked up in the fingers one can feel a slight tremor when the animal stridulates, although the sound is so faint that it cannot be heard farther than a few inches from the ear. What use, if any, is made of this sound is uncertain. 
Holmes, The Reactions of Ranatra to Light.

The method of sound production has been described by TORRE Bueno. The statement of this writer that the stridulation of Ranatra was not previously described is not correct, for the subject was briefly treated of by Locy ${ }^{1}$ in 1884 .

The instinct of feigning death, which is remarkably well developed in Ranatra, will be described in a subsequent paper.

\section{Reactions to Light.}

General Features of the Phototactic Response. When Ranatras are kept in a glass dish of water near a window they are usually to be found facing the light, often swimming towards it and repeatedly colliding with the side of the dish and clawing against the invisible barrier which blocks their course. These movements may be kept up, with intervals of rest, all day. When an artificial light is used the Ranatras may be caused to swim in any desired direction by placing the light in the proper position. In experiments with this species I have usually employed an ordinary i 6 candle-power incandescent lamp attached to a flexible cord of wire which permitted it to be readily moved about at will. The work was carried on in a darkened room so that the specimens experimented with were exposed to light only from this source.

When Ranatras are taken out of water and laid on a table they generally feign death, and, while in that condition, they at first give no reaction to light. One may move the light about near them or hold it almost against their eyes without eliciting the least sign of a response. This apparent insensibility, gradually wears away, and after some minutes the movements of the light are followed by scarcely perceptible motions of the head. By passing the light back and forth laterally over the body the head may be caused to rotate laterally each time the position of the light is changed. These are the first movements that can be made to appear, and they grow more decided the longer the experiment is continued. A little later the animal may be made to respond by vertical head movements

'Anatomy and Physiology of the Family Nepidae, Am. Nat., 1884, p. 364 . 


\section{Journal of Comparative Neurology and Psychology.}

when the light is passed back and fourth over the long axis of the body. When the light is in front the head is bowed down and when it is passed behind the body the head is tilted upward. Both the lateral and vertical movements are such that they tend to place the upper surface of the head at right angles to the direction of the rays. The vertical movements, like the lateral ones, are at first slight, and increase in vigor the longer they are caused to continue. The animal performs these movements with machine-like regularity and precision and without showing the least activity in any other part of the body. If the light is moved around the body in a circle the head will follow it with a corresponding rotary motion. If the light is in front and to the right of the animal the head will be tilted over to the right and at the same time pointed downward in front; or if the light is to the left and behind the animal the head will be tilted over to the left and raised up in front. For each position of the light there is a corresponding attitude of the head. The orientation of the head is remarkably precise. By carefully watching the tip of the beak with a lens as the light is moved it may be observed that a change of only two or three degrees in the direction of the rays produces a corresponding change in the direction in which the head is pointed.

After some time the movements of the head are accompanied by movements of the breathing tube. When the light is in front of the body the tube is lowered; when it is carried behind the body the tube is raised. These movements are at first slight but they become more decided and more regular the longer they are continued. Lateral movements of the breathing tube in response to light do not occur.

The next movements to appear are those of the limbs. The animal, after a time, shows irregular twitchings of the leg muscles, and soon afterwards slowly and unsteadily raises itself upon its legs and stands as if undecided whether to walk away or subside again into a state of repose. If now the light is passed over the body from side to side the creature will perform swaying movements each time the position of the light is changed. If the light is on the right, the back of the insect is tilted 
Holmes, The Reactions of Ranatra to Light.

over towards it, the right legs are flexed and the left ones extended (See fig. I). Pass the light over to the left side of

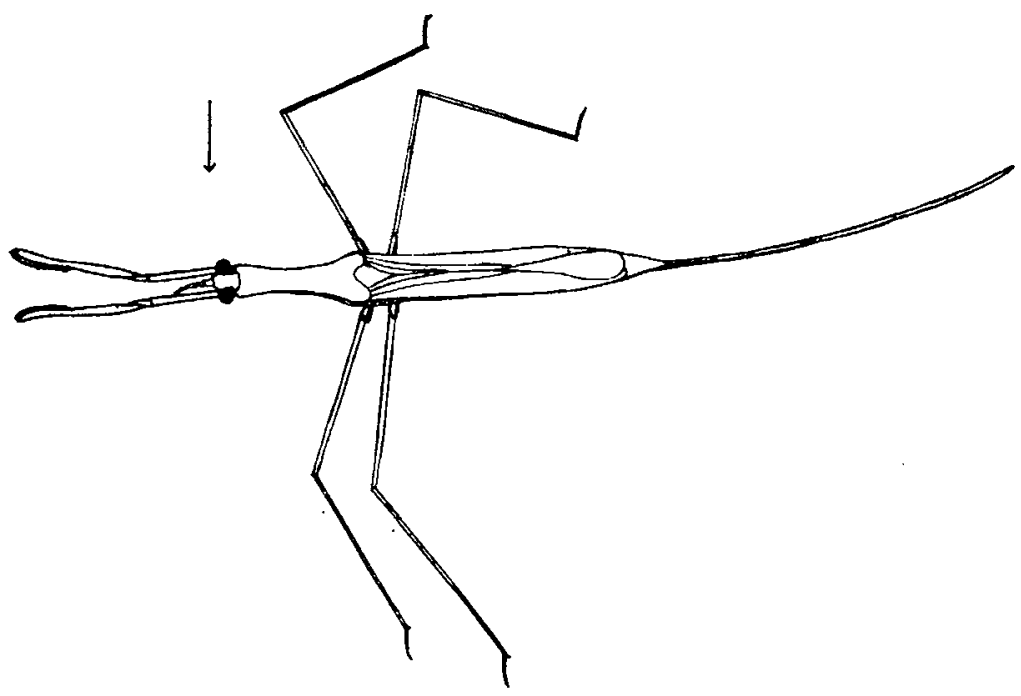

Fig. 1. Attitude of Ranatra when the right side is toward the light.

the body and the back tilts over to the left, the left legs become flexed and the right ones extended. For a short time after coming out of its feint Ranatra will usually sway back and forth as the light is moved over it without attempting to walk, but soon it begins to follow the light, at first with slow and unsteady steps, but later with more and more vigor, until finally its efforts to go towards the light become almost desperate, and it becomes oblivious to everything else.

Besides the lateral swaying movements which Ranatra performs when light is passed over the body from side to side there are equally pronounced longitudinal swaying movements when the light is passed back and forth along the axis of the body. When the light is placed behind the animal the body is raised up in front and the head held high in the air. Now place the light in front, and immediately the body is lowered, and the head bowed down, the grovelling attitude contrasting almost 


\section{Journal of Comparative Neurology and Psychology.}

comically with that assumed when the light is in the rear. By moving the light around the animal in a circle all combinations of lateral and longitudinal swaying movements may be produced, the body following the light by twisting about in a most curious fashion. With the light to the right and behind the animal the body is raised up in front, tilted over to the right, the legs on the right side flexed and those of the opposite side extended, the head turned to the right and the beak held high in the air. If the light is passed in front of the animal on the left side the head and body are both bowed down and tilted to the left, the left legs flexed and the right ones thrown in a state of extension. As with the head, so with the body, there is a certain attitude assumed for each particular position of the light.
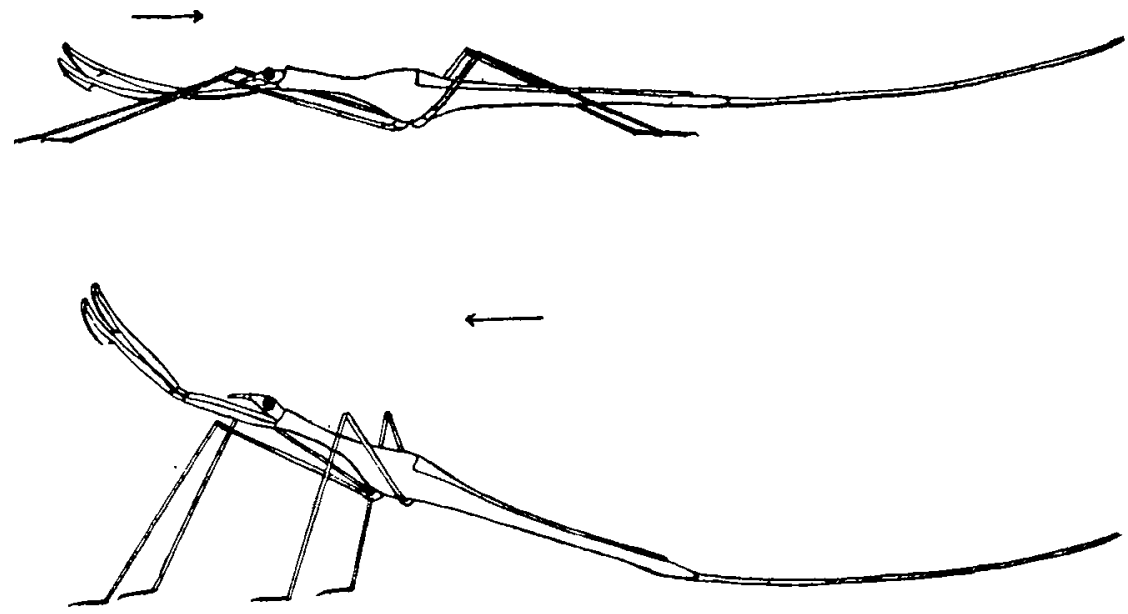

Fig. 2. The lower figure represents the position of Ranatra when the light is behind the body. The upper figure represents the position assumed when the light comes from in front.

Ranatras may be made to follow the light in any direction in the most slavish manner. By keeping the light to one side and a little behind the middle of the body the animal may be kept wheeling about in one spot, often, however, falling over on one side in its eagerness to get around. One reason for its awkwardness in this case is that as the light comes from the 
rear the anterior part of the body is carried high in the air and the creature consequently easily loses its balance.

At any time after Ranatra has ceased to feign death it can be made to perform swaying movements in either direction, although these may be combined with efforts at locomotion. By carefully controlling the light, however, the tendency to locomotion may be largely checked. By moving the light around the animal in a circle the tendency to turn back when the light is behind may be made to balance the tendency to go forwards when it is in front, and the animal simply sways around in its tracks.

Light seems to dominate entirely this creature's behavior when the phototactic reactions are once started. It does not manifest any fear or awareness of any object in its environment save the light which it so strenuously seeks. Its excitement increases the longer it is operated with, and after a time it may be picked up without feigning death, or with only a momentary feint. Not content with walking as rapidly as possible towards the light, the insect begins to fly towards it, always doubling up its fore legs in a curious manner before spreading its wings. The wings are never used, however, until the creature has sought for some time to reach the light by the ordinary method of locomotion. Their employment marks the attainment of a high pitch of excitement in which the insect seems animated by an uncontrollable frenzy which lasts until it is checked by approaching exhaustion.

If a Ranatra is placed on its back it often has considerable difficulty in righting itself, and if near a light it will often walk towards it without turning over. Locomotion under these circumstances is effected mainly by the anterior legs which are flexed dorsally at the middle joint. These legs are not employed in ordinary locomotion, but when the creature is in an inverted position they are used with considerable dexterity. By bending the legs dorsally the anterior end of the body is elevat$\mathrm{ed}$, and by the alternate movement of these appendages the insect walks along in a tolerably efficient manner. It will follow the light around in this way in any direction. When out 


\section{I6 Journal of Comparative Neurology and Psychology.}

of orientation it reaches over to one side with the anterior leg nearest the light and pulls the body over until it is parallel with the rays.

2. The Negative Reaction. While under ordinary circumstances Ranatra is positively phototactic it may in certain conditions become strongly negative. If Ranatras which have been kept for several hours in the dark are brought back again into the light they usually show a marked negative reaction, but this negative phototaxis is never so violent as the positive sometimes becomes. Instead of appearing to be the result of reflexes which are comparatively direct and involuntary, the behavior of Ranatra gives the impression of being caused by the desire to escape from a situation which is unpleasant. It is perhaps remotely analogous to the action of a man when, after having been for some time in the dark, he instinctively turns away from the sudden glare of a strong light. The behavior of specimens after having been kept in the dark may be illustrated by the following experiments :

Twenty-five Ranatras which had been in a dark room for twelve hours werc placed, one at a time, in a glass trough through which light was passed from an incandescent lamp situated a foot from one end. Each specimen was placed in the water in the center of the trough at rivht angles to the direction of the rays and let go in that position. If the specimen swam to the negative end, and within one minute returned to the other end when the light was changed it was classed as negative; and a similar criterion was employed for the positive reaction. If a specimen swam to one end of the trough and did not return to the other end within one minute after the light was changed it was classed as doubtfully positive or negative according to which end it first reached. Seventeen of the specimens proved to be negative; one was positive; four were doubtfully negative and two doubtfully positive. Out of the twenty-five specimens employed only one was unmistakably positive in its reaction, and this one swam to the positive end of the trough upon change of the light several times in succession. One spectmen did not swim to either end for five minutes. The Ranatras were then left exposed to the light of an incandescent lamp placed three inches from the end of the trough for one hour and forty minutes. At the end of this time all of the specimens were positive, The light was then held eight feet from the trough and the positive reaction still continued.

One of the specimens which showed a very marked negative phototaxis was singled out. During the time the others were being experimented with it was exposed to the light, and when again studied (after about a half hour's exposure) it showed a very evident negative phototaxis, but not so strong as before. After a time the negative reaction became so faint that it was scarcely distinguishable. 
Holmes, The Reactions of Ranatra to Light.

The specimen was then exposed to the strong light from a projection lantern. It showed at first a weak positive phototaxis which grew stronger the longer it was exposed, until it finally became almost violent. When exposed to the much weaker illumination from a 16 candle power lamp it still showed a marked positive phototaxis, but not so strong as when exposed to the light of a projection lantern.

At another time a Ranatra was placed in the trough which was exposed to the light of an incandescent lamp placed two feet from one end. The specimen immediately swam to the negative end of the trongh. When the lamp was placed two feet from the other end the specimen quickly returned. The light was then changed repeatedly several times and each time the Ranatra would swim to the negative end of the trough, usually within four or five seconds. After a time its responses became slower and less definite. The light was then held close to the end of the trough and the responses became as prompt as before. It was changed from one end of the trough to the other forty-two times, and each time the insect within four or five seconds went to the negative end. Then it was left several minutes, after which its negative responses became less marked. When it was exposed to the strong light of a projection lantern it was still negative. It was then taken out of the water and laid on the table. In a few minutes it came out of its feint and showed the usual swaying movements when an incandescent lamp was moved near it, but it was very reluctant to walk. After 15 minutcs of hesitation it became more active and showed an unmistakable positive reaction, and several times flew towards the light. When placed in the water again it still showed a strong positive phototaxis. The next morning (it was not in the meantime exposed to light, the room being darkened) it was markedly negative, and was driven from one end of the trough repeatedly by changing the position of the light. Then it was taken out of the water and placed on the table and an incandescent lamp was moved about near it to bring it out of its feint. It was a long time in awakening and for several minutes afterward it was disinclined to walk. When it did so it began to follow the light and soon became so excited that it would fly towards it repeatedly when four or five feet away, When put back into the water it was still positive and would follow the light in every direction. It was then exposed to the light from a projection lantern and became more strongly positive than ever, moving wildly towards the light even in the intense glare of the focus. Brought back to an incandescent lamp again it showed only a comparatively feeble response.

The negative reaction is associated with a condition of lowered phototonus. It is rarely shown except when the animal is in a condition of comparative sluggishness. When in great excitement, when its movements take place with quickness and vigor, Ranatra always shows a positive response. It never flies away from the light. Whenever it is wrought up sufficiently to use its wings, its reaction is invariably positive. The negative movements are slow and stealthy, often giving one the impression that the insect is attempting to sneak away unob. 


\section{Journal of Comparative Neurology and Psychology.}

served. The promptitude and decision of its negative movements may increase up to a certain point if the insect is kept close to the light, but when the movements begin to become vigorous there is a transition to the positive type of reaction. Often the advent of positive phototaxis is accompanied by a marked accession of energy as if a strong dormant propensity had suddenly been awakened.

The causes that produce the negative reaction are, as a rule, those which lead to diminished activity and excitement. Cold, exposure to darkness, the quieting effect of contact stimuli lead to a condition of lessened excitability and, perhaps as a result of this, to a negative reaction to light.

3. Head and Szuaying Movements in Negative Phototaxis. It would naturally be expected that the leg movements in negative specimens are the reverse of those in positive ones, and to a certain extent this is true. It was thought not improbable that the movements of the head would be reversed as well; but it was found that in all cases in which Ranatras moved away from the light the head reflexes take place exactly as in individuals that are positive. Both in strong and in weak light, under a variety of different conditions the head reflexes are the same in kind regardless of the general sense of the response.

The swaying movements in negative phototaxis are readily observed in Ranatras that have been resting quietly in the dark for some time in a glass dish of water. If an incandescent light be brought near them they are at first irresponsive. By moving the light slowly about them the head reflexes are first induced. Then there may be very slow and at first scarcely perceptible movements of the legs, the second and third pairs being very lazily extended on the side towards the light, and flexed on the opposite side, the back being rolled over so that it more nearly faces the light. On placing the light on the opposite side of the body there is a very gradual extension of the legs previously flexed and a flexion of those previously extended, the body rolling over at the same time so that its dorsal surface lies more nearly at right angles to the rays. The animal may be made to repeat this performance many times in succession. After a 
time its movements become more vigorous and it turns to walk away from the light; it can then be driven about in any direction at will.

The difference in the swaying movements of positive and negative specimens is mainly brought about by the different movements of the legs at the femoro-tibial joint. In negative specimens the legs on the side toward the light are extended at this joint while those on the opposite side are flexed; in positive specimens the reverse relation occurs. The rolling of the body is the same in both cases so that the muscles extending between the legs and the body are similarly affected in both kinds of reaction. The same relation probably obtains with the muscles between the joints of the upper parts of the leg. The vertical swaying movements of the body which involve the employment of these muscles are the same in both kinds of response. When light is behind a negative specimen the anterior part of the body is held high in the air as the insect walks away. When the light is held in front of the insect the anterior end of the body is lowered as it is turned from the light.

Only a part of the organism is subject to a change in the sense of its phototactic response. The head reflexes and swaying movements of the body are always such as to bring their upper surfaces more nearly at right angles to the direction of the rays, whether the organism as a whole is going towards or away from the stimulus. No matter how strong or how weak the light, or whatever may be the condition of the animal, these responses, if made at all, always occur in the same way.

4. The Effect of Contact on Phototaxis. As shown by the following records of experiments, Ranatra may be made negatively phototactic by means of contact stimuli. In one experiment seven specimens that were swimming against the side of the dish towards the window were picked up by their breathing tubes and dropped back into the water. At first they remained quiet but soon showed a negative reaction, swimming vigorously against the side of the dish away from the light. In about twenty minutes all but two had become positive again. They were all picked up by the breathing tube a second time 


\section{Journal of Comparative Neurology and Psychology.}

and dropped back into the water without touching any other part of the body. Soon all became negative without exception. After a few minutes they began to cross to the positive side of the dish one by one, and it was but a short time before every individual was positive. When I returned after an absence of an hour and a half all of the specimens were negative, although the light to which they were exposed had increased in intensity. Warm water was then added so as to bring the temperature of the medium up to $30^{\circ} \mathrm{C}$. Four of the specimens soon became strongly positive. These were picked up by the breathing tube and dropped back into the water; all became markedly negative. As specimens came over to the light side of the dish they were picked up and dropped as before, with the result, in almost every instance, of producing a marked temporary negative reaction. The next morning at ro o'clock all of the specimens in this dish and in another that was beside it were swimming towards the light. They were all picked up and dropped back into the water when, without exception, they became negative. Soon they began to come over to the positive side of the dish and in about half an hour they were all positive again. They were all picked up and dropped a second time. All but two became negative. At 2:40 in the afternoon the specimens in each dish were aggregated into a dense bunch at the negative end. When stirred up some seemed positive and some negative, but their reactions were not decided. The temperature of the water in one dish was increased to $32^{\circ} \mathrm{C}$. when about half of the specimens became positive in an unmistakable degree. When picked up and dropped into the water they quickly became negative. When they became positive again they were handled under the water without taking them out; as soon as released they showed an unmistakable negative reaction.

I have tried handling positive specimens under water repeatedly. The effect is, in nearly all cases, to produce a change in the sense of the phototactic response.

The effect of contact and disturbance is very marked also on specimens while out of the water. This as well 25 other 


\section{features of interest is shown in the following experiments per- formed upon one individual :}

The specimen was taken out of water from a darkened room where it had been placed the day before and placed near alight on a table. Soon it awoke and began to turn away from the light. The light was moved around it in different directions and, although the insect seemed at first dazed and walked about with no very decided tendency to go either towards or away from the light, it soon began to show a more pronounced negative reaction. It was then picked up by the breathing tube and placed at right angles to the rays from an incandescent lamp four feet away. During eight successive trials in which the right and left sides were presented alternately to the light to eliminate any tendency to turn to a particular side that might be due to habit, it turned in each case away from the light. Its movements were at first slow and stealthy. At the ninth trial it turned slightly towards the light, but reached the edge of the table before it had turned very far. At the tenth and several subsequent trials it turned towaws the light and went up to it rather quickly. Its movements now became much more rapid. It was then placed ten feet from the light and still showed a positive response. It was then placed on the floor 22 feet away from the light, which was laid on the floor at the other end of the room. Although the light to which it was exposed was relatively very dim, the insect traveled to the light across the whole length of the room in nearly a straight line. When brought near the light the insect became more and more strongly phototactic and in about twenty minutes its efforts to reach the light became almost frantic. After a time it became apparently exhausted and settled down to rest.

It was then immersed in water and laid down on the table. Its movements were very sluggish and its responses to light slow. When placed at right angles to the rays it would slowly and stealthily creep away. It did this eight times in succession when the right and left sides were alternately placed towards the light. At the ninth and several subsequent trials it went towards the light. Then it was caused to follow the light about for a few minutes and soon it became quite excited. It was picked up and stroked but it could not be induced to feign death and as soon as released it made for the light, which was four feet away. It was then held in water for several seconds, but as soon as liberated it showed an unmistakable though not very strong positive reaction. It went up to the light, touched the bulb with its anterior legs, jerked back quickly as if burned, then stopped for a moment and walked away from the light. As the light was. moved about, the insect would flee from it repeatedly as if it feared a repetition of its disagreeable experience. Soon, however, its responses became weak and indefinite; its movements were sluggish. After a time it showed a positive reaction and began to follow the light all around the table. A little later it became much excited and flew towards the light repeatedly. The light was placed in a cylinder of water and the insect struggled to go towards it for ten minutes. It was then held in cool water for a short time and placed again on the table. After this experience it showed a marked negative response. The light was moved about the insect in various directions so as to keep it close to the body for about twenty minutes when positive phototaxis was again induced. When its reaction became very strong, the insect was picked up and stroked, but it feigned 


\section{Journal of Comparative Neurology and Psychology.}

death only momentarily and then resumed its efforts to go to the light.

A repetition of the experiment was followed by essentially the same result. When dipped in water again it showed a faint nogative reaction. It would go towards the light when it was placed in front of the body or away from it when it was placed behind. Its general behavior was sluggish and it would perform only scarcely perceptible swaying movements when the light was moved over its body. Soon its negative reaction became more pronounced and it would turn away from the light every time it was placed to one side of the body. The insect was then placed under a bell jar near the light and upon my return after a two hours absence it was markedly positive. When dipped in water it showed a suggestion of a negative reaction, and for some time was apparently indifferent to the light. Repeated dippings failed to make the specimen more negative, and after a time a sluggish positive response began to appear. The light was then moved around it and finally the creature became very violent in the eagerness of its response and flew towards the light several times. When it was dipped in water it became sluggish. When placed at right angles to the rays it turned away from the light and started to do so a second time, but turned towards the light and went up to it. The same experiment was repeated three timcs in succession, and each time the insect turned at first away from the light and then towards it before having proceeded more than a few inches. After thirty minutes of positive reactions it was dipped in the water again. It went slowly towards the light but passed by it, and in several subsequent trials went away from the light; soon, however, it became weakly positive and in a short time its positive response was strong. After three hours of exposure to strong light it was still positive. When dipped into the water it showed at first a faint negative response but soon turned and went up to the light. Subsequent dippings failed to evoke a negative response.

It is not the effect of water in itself that changes the response, but the experience of being dipped in water. If the Ranatras are allowed to remain in the water they soon show a positive reaction. If then they are lifted out and $p$ ut on the table they almost at once become negative if they are not thrown first into the death feint. Curiously enough, dipping into water is more effective in changing the sense of the response than handling or stroking the specimens in the air. Specimens which have been handled so much that they no longer respond to that treatment either by feigning death or by showing a negative response to light may usually be rendered negative after dipping into water.

As handling positively phototactic specimens usually causes their reaction to become negative, unless the experiment is repeated too often, it is probable that the change produced by dipping them in water is due to the influence of contact stimu- 
li. It takes place independently of differences of temperature, and it cannot be satisfactorily accounted for by attributing it to chemical or osmotic changes produced by the surrounding media. Anything which makes towards the peculiar nervous condition which accompanies the death feint tends to produce the negative response. Dipping Ranatras into water usually throws them into condition of quiet when other influences fail, and the negative reaction is doubtless a result of the nervous state thus brought about. When a Ranatra is either placed in the water or removed from it, every portion of the surface of the insect is stimulated, and, although the stimulus upon no part is strong, the general effect may well be considerable. That the general integument is very sensitive is indicated by the fact that decapitated specimens often respond very strongly to the slightest breath of air.

5. The Effect of Temperature on Phototaxis. Raising the temperature tends to accentuate the positive phototaxis in Ranatra and lowering it tends to produce the negative reaction. In several experiments two dishes containing Ranatras were set before a window so as to receive the same amount of light. As the specimens had been previously kept in the dark, they showed a negative reaction. Into one dish warm water was poured raising the temperature from about $20^{\circ} \mathrm{C}$ to nearly $30^{\circ} \mathrm{C}$. In a few minutes the specimens in the warmer dish became positive, the ones in the cool water still showing a negative phototaxis. Ranatras transferred to the cooler dish soon became negative while those which were picked up in the same way and dropped back into the warm water from which they were taken soon resumed their positive reaction. On the other hand, transferring negative specimens from cool to warm water produced in a short time a positive response. In cool water there is a marked tendency to form a dense cluster in the negative end of the dish. In warmer water the insects become more active and the groups are more apt to be broken up. Water at a temperature of $30^{\circ} \mathrm{C}$ usually stimulates them to very energetic movements. That negative phototaxis in Ranatra is induced by a reduction of temperature affords an illustration of 


\section{Journal of Comparative Neurology and Psychology.}

the general fact that circumstances which reduce the excitability of the insect tend to produce the negative reaction.

6. Phototaxis Leading to Fatal Results. Wishing to ascertain if Ranatra would continue to be positively phototactic if it were thereby led into a situation which exposes it to stimuli having injurious, if not fatal, effects I performed the following experiment.

A strong arc lamp was placed on a table so that the focus or space between the carbons was about five inches from the top, this elevation being chosen so that the specimen could not walk directly into the luminous arc although it was free to move about beneath it. As the lamp gave out a large amount of heat the insect in approaching the focus would he brought into a region sufficiently heated to produce a fatal effect if it remained there long. A Ranatra placed on the table, moved toward the light until it came under the focus, then starting off again, only quickly to return. It soon became wildly excited and made repeated dashes toward the light. Several times it flew towards it, but luckily escaped coming between the carbons. After a time it gave signs of being overcome with the heat, but whenever removed from the light it would quickly return. Its movements became weaker, although its efforts to go to the light were no less persistent. It became unable to raise its body off the top of the table as it walked, but used its legs to slide its body towards the light, and it would quickly re-orient itself when placed obliquely to the rays. Even its very last piteous efforts were devoted to pushing its body a little nearer the light. When no longer able to move it was placed in cool water, but it did not revive.

When a moth flies into a flame it is probably because it does not have time to check or change the course of its fight after it has drawn near enough to experience the injurious effects of the heat. The suicidal conduct of Ranatra, however, cannot be accounted for in this way. The movements of the insect are slow and deliberate enough, especially when it becomes weakened, so that it need not be carried by its momentum into a region from which it would otherwise flee. It reacts positively at every step, even when nearly overcome by the heat. Essentially the same phenomenon is seen in Talorchestias which when exposed to direct sunlight, keep jumping towards the light until the heat overcomes them and they die.

7. Inhibition of Phototactic Responses by other Activities. The phototactic responses of Ranatra which usually occur with such regularity and precision are sometimes checked when the insect is engaged in performing some other function. Specimens that have been following the light for some time often 
stop to rub their eyes with their first pair of legs, using their claws in what seems to be an effort to scrape off some foreign object from the cornea. If a light is moved over an insect when it is engaged in this operation the swaying movements of the body will no longer be performed. The head reflexes are also sometimes inhibited, but usually the head can be kept moving about at the same time the insect is rather ineffectually attempting to rub its eyes. The swaying movements are likewise inhibited when Ranatra stops to rub its wings or any other part of the body. These actions may be caused by daubing asphalt varnish upon the insect, when efforts are made to get rid of the offending substance. As soon as the cleaning movements are over the insect promptly reacts to light as before. It generally makes no attempt to do two things at once.

The phototactic response may also be inhibited by efforts to obtain food. Ranatras which are swimming towards the light can often be caused to discontiuue their phototactic efforts if several small insects are placed near them. If the phototactic activities are very lively and vigorous it is more difficult to divert the attention of the insect to the capture of prey. When attention is once directed to seizing the smaller insects the light is disregarded. When the prey has once been captured and the Ranatra is engaged in sucking out its juices little attention is paid to the light. The repast being finished the insect may resume its positive response.

Efforts to go towards the light are frequently inhibited by contact stimuli. When several individuals are put into a dish of water near a window they commonly cease, after a time, to swim towards the light and form a dense cluster in which they lie at all possible angles to the direction of the rays. If now the individuals are placed in separate dishes they soon show a positive phototaxis. When placed together again they quickly form a group as before. Contact stimuli not only inhibit positive phototaxis but they produce a negative reaction as we have already seen: the latter tendency however, is often held in check by the same cause by which it is brought about.

Phototactic activities may also be checked by the sudden 


\section{Journal of Comparative Neurology and Psychology.}

appearance of a large object in the field of vision. Ranatras that are swimming towards the light generally check their movements and lie perfectly quiet for some minutes as soon as they perceive one's approach, but if no movement is made near them they soon resume their phototactic activities. This inhibition of movement recalls that which in higher forms is often brought about by fear, but of the usual manifestation of fear in the efforts to escape from enemies by flight Ranatra evinces no sign.

Control in Ranatra probably amounts to nothing more than supplanting one instinctive tendency by another. The reactions of the insect to light seem to take place inevitably unless some circumstance calls into play some other equally stereotyped form of instinctive response.

8. The Effect of Hemisecting the Brain. Cutting the brain of Ranatra through the middle was accomplished by means of a fine needle ground down to a sharp edge. Only a small opening need be made, and there does not follow the profuse bleeding which results from making larger incisions. After hemisection of the brain specimens are easily kept alive for several days. Their behavior may be illustrated by the following records of experiments :

The brain was hemisected in three specimens;at $8: 45 \mathrm{~A}$. M. In one minute or less they came out of their death feint; in five minutes they were picked up and stroked and then laid on the table. None feigned death for more than two or three seconds. At 9:25 they were still very restless and none of them paid the least attention to the light that was held near them. They all performed circus movements to a greater or less ertent, due, doubtless, to the fact that the brain was not cut exactly through the middle. At II A. M., one flew out of the dish They were all picked up aud stroked again, but none feigned for more than a few seconds. When the light was moved about near them they would show no head reflexes or other decided response, although the light seemed to stimulate them in an indefinite way. During the next two or three days they continued the same restless movements and could be induced to feign death only for few seconds. Definite responses to light failed to return.

The brain in three other specimens was hemisected at $12 \mathrm{M}$. They all soon came out of the death feint that was induced by handling them during the operation. At $1: 20$ P. M., when they were again observed, they were very restless. When picked up, stroked, and laid on the table they feigned death for one minute, four minutes, and ten minutes respectively. The next day they could not be induced to feign for more than a minute and they showed no definite response to light. They were also tried on each of the three following days and their be- 
havior was essentially the same. Two specimens seemed to respond when the light was moved near them but when the rays were passed through water before reaching them no response could be evoked. It is probable, therefore, that their movements were the result of stimulation by heat. Ranatras with the-brain cut through the middle, like those with the brain removed, are very sensitive to all sorts of stimuli, and they are set into action by causes which would produce no manifest effect in a normal individual.

Bethe ${ }^{1}$ found that hemisecting the brain of Carcinus caused the phototaxis of the animal to disappear, although most of its other responses took place in a normal manner. I have found the same in sevaral species of insects. In the amphipod Talorchestia longicornis, which has a remarkably strong positive phototaxis, hemisection of the brain is followed by a complete loss of the power of orientation. Sensitiveness to light, however, is not entirely destroyed. If when a specimen is resting quietly in a shaded spot a beam of light filtered through an alum cell is thrown upon its eyes it usually responds by a few irregular movements. Since a large part of the fibers of the optic nerves cross in the brain, hemisection of this organ cuts off the main path of the impulses concerned in orientation to light.

9. The Effect of Covering the Anterior Half of the Eyes. Ranatras with the anterior surface of both eyes blackened over walk with the head strongly upturned and the anterior end of the body high in the air. Sometimes they stand nearly vertically, and several times I have seen them fall directly over backwards. Even when going towards the light the anterior part of the body is elevated, but not so much so as when the light is held above or behind the insect. When the light is moved backward and forward above the insect the body sways to and fro, and the head responds with the usual vertical reflexes. When the light is behind the insect the head and front part of the body are much elevated; if now the light is carried to the front the creature bows down only for a short distance instead of assuming the grovelling attitude of a normal individual in the same situation.

\footnotetext{
${ }^{1}$ Archiv f. mik. Amat. 1897, 50, 617.
}

2Am. Jour. Physiol. 1902, 5, 211. 


\section{Journal of Comparative Neurology and Psychology.}

When Ranatra is compelled to walk on a glass plate while the light is held beneath the body it still carries the head and anterior part of the body high in the air. The head and body are lowered somewhat if the light is placed below and in front of the insect, but not nearly so much so as in a normal specimen. If the light is passed to the rear beneath the glass plate the head and front part of the body are raised up. Lateral head and body movements are performed in the usual way when the light is passed transversely over the posterior part of the body, but as the light is carried forwards these movements become less marked. Similar results are obtained if the light is moved beneath an insect which is placed on a glass plate; the responses become less evident and precise as the light is carried in front of the body.

Ranatras with the anterior surface of their eyes blackened over are still able to follow the light when it is in front of them, but their movements are hesitating and their orientation inaccurate. This is a very natural result since the insects must be guided by the light which enters the posterior sides of the eyes.

1o. The Effect of Covering the Posterior Half of the Eyes. Blackening over the posterior surfaces of both eyes produces effects opposite to those observed when the anterior surfaces are blackened over. The insect walks with the anterior part of the body lowered and the head inclined slightly downward. If a light is held behind the insect the head and anterior part of the body are elevated, but not so much so as in a normal individual. When the light is in front the body is lowered anteriorly and the head bowed down. The same effects are produced when the Ranatra is placed on a glass plate and the light moved beneath the body. The light is followed very readily when it is kept in front of the body; if, however, the light is moved to the rear the insect experiences considerable difficulty in orienting itself and frequently travels for some distance directly away from the light before finally turning around. Lateral movements of the head and body are readily brought about when the light is moved from side to side in front of the insect, but they become less pronounced when it is carried further back. 
Hocmes, The Reactions of Ranatra to Light.

II. The Effect of Destroying or Covering One Eye. If one eye of Ranatra is blackened over or destroyed the insect in most cases no longer walks in a straight line but performs more or less decided circus movements towards the normal side. Under the stimulus of light the insect assumes a peculiar attitude; the body leans over towards the normal side and the head is tilted over in the same direction. When a light is held opposite the normal eye the insect leans over towards it, and holds the legs nearest the light in a flexed condition while those on the other side of the body are extended. When the light is passed over the body transversely swaying movements are performed as long as the light is opposite the normal eye, but when it is passed to the other side of the body the insect sways back only to the middle position or slightly farther. The longitudinal swaying movements of the body and vertical movements of the head are performed when light is moved forward and backward above the insect. These movements become less decided, however, as the light is held over towards the blind side.

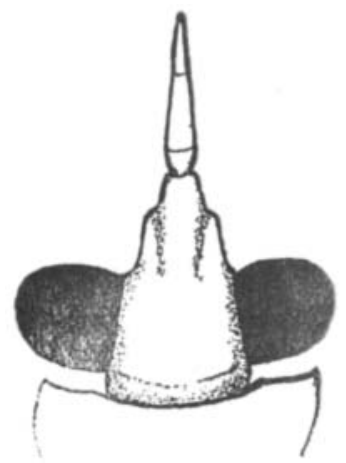

Fig. 3. Head of Ranatra fusca showing the almost stalked condition of the eyes.

If a light is held directly in front of a Ranatra with one eye blackened over the insect frequently does not travel straight towards it, but veers over towards the normal side until it comes to go in a quite different direction from that in which it 


\section{Journal of Comparative Neurology and Psychology.}

started out. In one experiment a Ranatra with the the right eye blackened over was placed at a distance of four feet from a I 6 candle power lamp. In all of the twelve trials that were made it started on a nearly straight course towards the light as it was originally pointed. In all cases it veered to the left and naturally diverged from the straight path more and more the farther it proceded. When a little more than half the distance to the light had been covered it corrected its course and proceeded towards the light again in a more direct path. This took place by two methods and usually occurred when the normal eye was looking away from the light. In this situation the insect would frequently stand for some time as if undecided which way to turn. In four instances it turned towards the right and proceeded again in the direction of the light. In eight cases it continued turning to the left until it had gone completely around in a circle after which it went up to the light.

Specimens with one eye blackened over present, however, marked individual differences of behavior. In some cases the insect walks toward the light in a nearly straight line. Ranatras which were taken late in the fall or early in the winter in most cases went nearly straight to the light while those experimented with in the early fall usually performed circus movements. This difference may have been due to accidental individual differences in the specimens, or it may have been the result of differences in age, the older Ranatras being better able to correct their course than the younger ones. The tendency to turn away from the blind side is manifested to a greater or less extent in all cases, but in many specimens it does not go so far as to produce decided circus movements.

If the whole of one eye and all but the posterior surface of the other is blackened over the insect in many cases is still capable of following a nearly straight path towards the light. A tendency to perform circus movements is more or less manifest and many specimens will go around in a circle repeatedly, especially when the light is near them. When all but the posterior surface of one eye is blackened over the insect is able to guide itself to the light nearly as well as when one eye is entire. 
Hormes, The Reactions of Ranatra to Light.

ly exposed. It may even follow the light by turning towards the blind side as the following experiment shows :

The right eye and all but a small part of the posterior surface of the left was thickly blackened over. When the specimen came out of its death feint it walked nearly straight to the light. The light was then moved over toward the right side of its path several times, and the course of the insect was changed so as to continue going towards it. The light was then held to the right and behind the body and the insect circled around to the right. By keeping the light in the proper position the insect could be caused to keep circling around to the right in the same spot. The head and body in these movements were tilted over slightly to the right, but not so strongly as they are inclined to the left when the light is held on that side. The insect would perform circus movements to the left more readily than in the opposite direction, but it would make sharp turns to the right whenever it was necessary to maintain a position of orientation. When the light was placed behind the body the insect would usually turn around to the left to reach it. If, however, it was placed behind the body and a little to the right the specimen would turn around towards the right side.

12. Reactions of Specimens with only Small a Part of the Lateral Surface of One Eye Exposed. The right eye of a specimen was completely blackened over and all but a small part of the lateral surface of the left.

The insect was at first sluggish. When the light was held on the left side the head and body were tilted over towards it, and the specimen turned slowly to the left. When the light was placed two feet ahead of the specimen it moved very slowly and with the greatest hesitation, turning this way and that as if seeking to get its bearings, but going, nevertheless, nearly straight to the light. Although a decided tendency to make circus movements to the left was manifest, deviations in that direction were corrected by a direct turn towards the right side. When the light was held on the right side of the body the insect seemed confused and undecided which way to turn. When the light was held to the front and to the right so that the rays struck the body at an angle of about $45^{\circ}$ the insect would not turn towards the light but moved about aimlessly until the left eye was presented to the light when it would turn to the left and go up to it. By keeping the light nearly in front of the body the insect would follow it all around the table. The experiment was then tried of holding the light farther over towards the right. The insect could then be caused to keep turning slightly towards the right in order to follow it. When the light was held still further to the right the insect still followed it. After a while it would follow it when held in a position to which it would not turn at the beginning of the experiment. After having got into the way of turning to the right side it would turn in that direction much more abruptly than at first.

A second specimen was treated in the same way, but it showed at first a pronounced negative reaction. It would pay little attention to the light except when it was held opposite the left eye when the insect would move away from it sidewise, much like a crab, by extending the legs on the left side and flexing 


\section{Journal of Comparative Neurology and Psychology.}

those on the right. When the light was held on the blind side the insect showed no inclination to turn away from it. The movements of the insect were slow, but, after about twenty minutes, it suddenly began to turn vigorously to the light and became much more active, following the lamp around with eagerness and rapidity. In several trials in which it was placed three feet away from the iamp it went towards it in nearly a straight line, correcting its deviations from a straight course, whether to the right or the left, by the appropriate turn. It soon became quite excited and several times attempted to fly. It would follow the light when it was in front and to the right side by turning directly to the right. If, when the light was reached, it was changed to some other part of the table the insect would turn around and make for it in nearly a straight line. After moving about in this way for some time it settled down so as to rest its body against the top of the table. The light was then placed near the specimen, but it paid no attention to it until it was moved opposite the left eye, when it began to move slowly away from it by crawling sideways. The whole character of the insect's behavior now became suddenly changed. It became sluggish and stealthy in its actions instead of vigorous and excited. It would respond to the light by moving sidewise instead of straight ahead, and only when the light was placed in a certain position. After moving the light around the specimen its negative reaction became more decided and then suddenly changed to positive. It would follow the light around either to the right or to the left, but if the light were held too far to the right side it would not turn directly towards it. The specimen had several other fits of reacting negatively when its conduct was essentiaily as described above. It was caused to become positive each time by keeping the light near the left eye. Its negative reaction would in each case grow more vigorous and then suddenly give way to the positive response. The appearance of the positive response seemed to indicate the attainment of a certain degree of excitement.

The differences between the negative and positive responses of the specimens experimented with are very striking. The peculiarites of the negative reaction are probably due to the fact that only when the light shines directly into the left eye is the stimulus strong enough to produce action. When out of the direct glare of the light the insect is content, and it gets away by the most direct method. In the positive reaction the insect is attempting to get more of the stimulus; it is in a state of increased phototonus, and each movement that brings it nearer the light tends to increase its activity.

13. Phototaxis as Modified by Experience and Habit. That Ranatra is able to modify its reaction to light as the result of experience was shown by several experiments. The attempt was made to determine if Ranatras which perform circus movements when one eye is blackened over would in time come to 
travel to the light in a more direct course. A Ranatra with its right eye blackened over was placed on the top of a table three feet away from an incandescent lamp. Each time the specimen reached the lamp it was picked up by its breathing tube and placed in its original position facing the light. The course over which it traveled was in each case followed by a pencil. The paths taken in successive trials are represented in the accompanying diagram (Fig. 4).
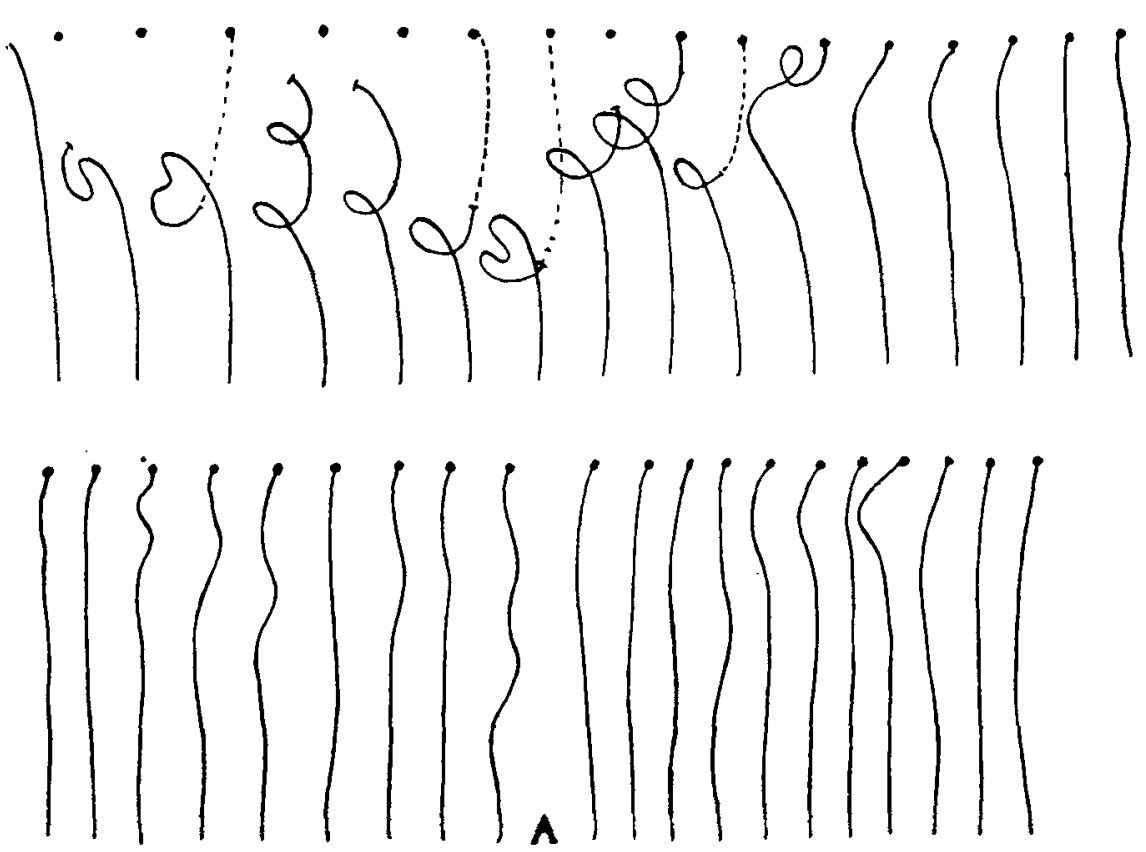

Fig. 4. Paths taken by a Ranatra in successive trips to the light. The position of the lamp is indicated by a dot at the upper side of each path. The cross lines indicate places where the insect took wing. When it flew directly to the light its course is represented by a dotted line. At $A$ the experiment was discontinued for fifty minutes, after which the remaining tracings were taken.

The specimen showed a strong tendency to fly as it drew near the light, and after the tenth trial its wing covers were stuck down by asphalt varnish. After a few ineffectual attempts to raise the wings the insect gave up trying to use them and walked to the light more quickly and with fewer pauses. The 


\section{Journal of Comparative Neurology and Psychology.}

points on the path where the specimen took flight are indicated by a short cross line, and the position of the lamp is represented by a dot.

In the first trial the insect veered over constantly to the left, passed by the lamp and went off from the table before it turned around. In the following trials a marked tendency to turn to the left is also shown; frequently the insect makes one or more complete circus movements to the left before reaching the light. At the eleventh trial its course is corrected for the first time by a turn to the right side, but, instead of going straight up to the light, it performed a complete circus movement to the left before reaching it. The next time the course was corrected by a sharp turn to the right and the circus movement was dispensed with. At the next trial the course was corrected in the same way, and at the fourteenth attempt the insect deviated only slightly to the left side and then turned to the right to reach the lamp. In the following ten trials it reached the light by a nearly straight path. Whenever it began to turn away from the light to the left it corrected its course by a direct turn in the opposite direction instead of going around in a complete circle as at first. During the latter half of the experiment the insect became more excited and walked to the light more rapidly and with less hesitation and wavering. The experiment was discontinued at $12: 10$ P. M. and resumed at I P. M. The insect had not forgotten in the meantime how to reach the light by the most direct means. In eleven trials it went to the light in nearly a straight course, as is shown by the second series of tracings.

The specimen was then placed with its left side towards the light. In each of its successive trials it turned sharply to the left and went up to the lamp. It was then placed with its right or blind side towards the light. In the first two trials it turned sharply towards the light and went up to it. In the third trial it first turned towards the light, but soon veered over to the left and went away from the light instead of towards it. When placed again with its left side to the light it no longer went towards it as before. It manifested a decided negative phototaxis in fifteen successive trials. When placed facing the light, as in the first experiment, it turned sharply to the left and went away from it for three times in succession. Then a fit of positive phototaxis began to manifest itself again. In the fourth and fifth trials it reached the light by an irregular course. After this it went nearly straight to the light fourteen times. It was now allowed to rest for an hour and a half, when it was experimented with again. At the first trial it turned to the left, but corrected its course by a turn in the opposite direction and reached the lamp. In the second trial it went to the lamp in nearly a straight line. At the third attempt, after it had gone nearly to the light, in an almost straight line it turned away from it and went off in another direction. A fit of negative phototaxis now began to assert itself and in the next thirty trials it turned to the left and went away from the light. It was now nearly exhausted and could scarcely raise its body from the table. When near the light it would move in an excited manner in an effort to get away from it, but when it reached a darker region its movements became much slower, and it would soon come to rest. The experiments were then discontinued until the following day, when the specimen proved to be still strongly negative. After fifteen trials were made, in which it turned away from the light, except during a short fit of 
positive phototaxis, when it turned twice towards it, the specimen was put back into the water. At one o'clock on the day following, it was taken out again. It still showed a decided negative reaction and turned to the left and went away from the light twenty-five times in succession. In nearly all cases after it had turned its back upon the light it went away from it in nearly a straight line.

After a rest of an hour and a half the asphalt varnish was remored from its eye. When placed on the table, three feet from the light, the specimen went towards the light and passed by it, but it turned around before proceeding very far and went up to it. After this it went to the light eleven times in nearly a straight line. The left eye was then blackened over. In the first two trials the insect veered slightly to the left, but reached the lamp by a turn to the right. In the third trial it turned sharply to the right and went off from the table. In the fourth trial it went straight to the lamp. After this another fit of negative phototaxis apparently seized it, for it turned from the light and walked away from it in numerous trials. It then became fatigued and the experiment was discontinued. It is worthy of note that while the insect, after one eye was first painted over, came to take a direct course to the light only after several trials, it went to the light, when the opposite eye was painted over in nearly a straight line at the frst attempt. Unfortunately the fit of negative phototaxis which supervened prevented observation on this point from being carried out as fully as would be desirable. Owing probably to fatigue or frequent handling, the specimen became more prone to react negatively the longer it was worked with, until it no longer served the purpose of the experiment.

Other experiments showed a similar straightening of the course after a number of trials. As experiments on this subject were undertaken late in the season, most of the inviduals worked with went nearly straight to the light at the first trial. In one case a specimen went nearly straight to the light six times in succession; it was then taken up and its right eye given another coat of varnish to make sure that it was entirely covered. When put down again it seemed confused and performed a number of circus movements to the left. After several attempts, however, it came to travel to the light in nearly a straight line.

Similar experiments were tried on Notonecta with much the same results. These insects when placed on a table near a lamp travel towards the light with much eagerness. If one eye is blackened over they perform circus movements towards the normal side. After quite a number of trials, however, the Notonectas come to take a nearly straight course to the light. When they become deflected from their course they orient themselves by a direct turn in the appropriate direction. If the 


\section{Journal of Comparative Neurology and Psychology.}

lamp is kept over towards the blind side they may be made to perform circus movements in a direction opposite to that in which they would otherwise tend to go.

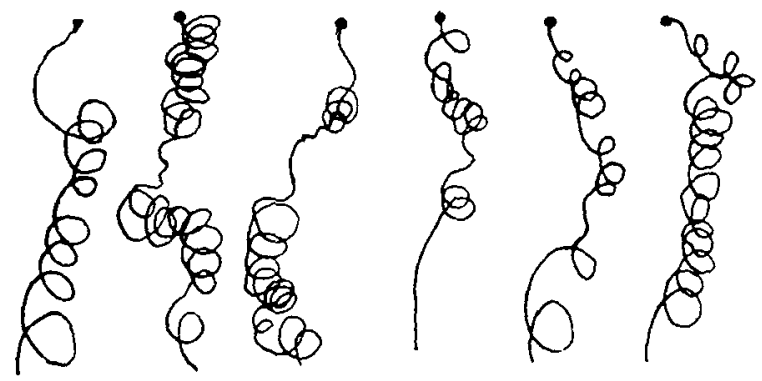

Fig. 5. Tracings of successive paths towards the light taken by a Notanecta, which had the left eye blackened over. After a number of other trials the specimen came to travel towards the light in nearly a straight line.

14. Formation of Habits of Turning. In working with Ranatras I have several times noticed what appeared to be a tendency to fall into habits of action, and I was naturally led to test the matter further by experiment. A Ranatra with its right eye blackened over was placed so that its head pointed

L directly away from a lamp three feet behind its body. As was to be expected, the Rana-

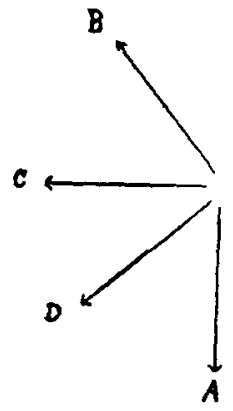

Fig. 6 . tra turned around to the left and went to the light. It was then picked up and placed in the same position ten successive times. In each trial it turned to the left and went up to the light as at first. In these and all subsequent trials the insect, when picked up, was turned alternately to the right and to the left before it was put down again. In this way the possibility that the results might be due to compensatory motions was eliminated. After the first ten trials the insect was placed obliquely (at an angle of $45^{\circ}$ ) to the rays with its right side towards the light (position B in Fig. 6). In each of the ten trials that were made the insect turned towards the right or blind side, and went to the light. It was then placed 
at right angles to the rays, the light falling on its right side as before (position $\mathrm{C}$ ). In each of the ten trials made it turned towards the right as in the previous experiment. Then it was placed with its head pointing obliquely away from the light (position D), when it still turned to the right in each of ten successive trials. Finally, it was put back into its original position, A, with its head pointing directly away from the light. Instead of turning to the left, as it did at first, it turned to the right as in the experiment immediately preceding, and it repeated the performance in the same way ten times in succession. It was then placed in a slightly oblique position so that its left side was exposed to the light. Twice it turned to the right as before, but in the third and several subsequent trials it turned to the left. It would then continue to do so when placed back in its original position, or even with its right side slightly turned towards the light.

The experiments afford unmistakable evidence that when Ranatra has turned in any direction once it tends, ipso facto, to turn in the same direction a second. time. The habit thus formed may even overcome the tendency to turn towards a particular side which is caused by blinding one eye.

IV. General Considerations on the Phototactic Response.

The behavior of Ranatra in relation to light is, I believe, not without interest in relation to the general theory of the phototactic response. Many features of the phototaxis of this insect seem to afford strong support to the reflex theory. The perfectly definite and regular movements of the head in response to changes in the position of the light and the fact that these movements take place under all conditions in exactly the same way indicate that they are as machine-like as the most devoted partisan of the reflex theory of tropisms could wish. There is no evidence of choice, properly so called, in the performance of these actions. It is true that during the death feint they are no longer performed, but this affords no ground for regarding them as in any sense voluntary, since, as is well known, undoubted 


\section{Journal of Comparative Neurology and Psychology.}

reflexes are no longer performed in certain conditions of the nervous system.

The swaying movements of the body in response to changes in the position of the light seem almost as mechanical as the head reflexes. They are more easily inhibited, however, since they are often checked by efforts to rub the eyes, to clean the body, or to raise the wings after they have been fastened down, but they are immediately resumed as soon as the energies of the insect are no longer diverted to other actions. The swaying movements of the body are the result of a strong and definitely directed tendency to action which, when the insect is in a certain condition of tonus, it seems powerless to control. It is only when other instinctive responses are brought into play that the insect is able to overcome its phototactic activities.

The swaying movements of the insect vary, however, according as it reacts to light in a positive or a negative manner, but there is little evidence of choice as regards which mode of response is followed. In one nervous condition the insect is always negative; in another condition it is always positive. A Ranatra that is lethargic and sluggish reacts to light in a negative manner, while one that is highly wrought up and excited is always strongly positive. In intermediate states of excitement there is often a hesitation between the two modes of response, and the insect may exhibit alternate fits of positive and negative phototaxis of short duration. The power of one instinctive response to inhibit or overcome another may be considered as the first step towards the voluntary control. Choice as manifested by Ranatra is determined by which of two instinctive tendencies to action gains ascendency.

The mechanical nature of the phototactic response is further evinced by the effect of blackening over different parts of the eyes. When the posterior sides receive light the legs are extended and the anterior part of the head and body are held high in the air. When only the anterior sides receive light the head and body are bowed down. If light comes in only at the side of one eye the legs are flexed on the side towards the light and extended on the side away from it. It would almost seem as 
if different areas of the compound eyes have special connection with particular sets of muscles such that when a given area is stimulated the muscles are set in action which bring about a particular attitude of the body.

We should bear in mind the possibility of interpreting the phototaxis of Ranatra as due to the fact that the light is sought because the insect derives from it an agreeable stimulus. We might regard the creature as so constituted that it derives pleasure from light and reacts toward it so as to get as much of this stimulus as psssible. Its behavior would then come under the head of what BALDwin calls the "circular reaction." The movements of the head and body would be interpreted, according to this conception, as efforts to place the body in such a position that it can receive more of the desired stimulus. Whatever the position of the light Ranatra reacts towards it so as to place the upper side of the head more nearly at right angles to the direction of the rays. Both the head movements and the swaying movements of the body conspire to this end. And in this position it is probable that more light is received by the eyes than in any other.

Whatever may be the explanation of the process in physiological terms, it is evident that animals perform many actions simply because they derive pleasure from so doing. Such actions are, I am inclined to believe, not quite the same as simple reflex acts, even in such a creature as Ranatra. Simple reflex acts may, however, be accompanied either by pleasure or by pain, although neither of these states nor their nervous correlates determines the nature of the reaction. But in most cases of the pleasure-pain response the character of the nervous analogue of these states somehow determines whether movements producing them shall be continued or inhibited. Movements which bring agreeable stimulation are persisted in, while those which produce painful effects are checked. If any stimulus brings a pleasant sensation an animal is apt to make efforts to get more of that stimulus. If the creature possesses any power of association, movements bringing an increase of the stimulus are repeated and come to be performed with ever increasing 


\section{Journal of Comparative Neurology and Psychology.}

readiness. In view of the fact that insects are capable of forming quite complex associations and of guiding their action by their previous experiences there is no reason to balk at the admission of the possibility that an insect may seek the light because it thereby derives an agreeable feeling. Whether the phototaxis of Ranatra is to be interpreted as a form of pleasure seeking, or as a matter of direct reflexes, a sort of behavior forced upon the creature from without, is a question not to be decided without careful observation and experiment. That an organism travels towards the light in the direction of the rays, even though it goes from a brighter area into a darker one, is no decisive proof of the latter theory. We might interpret the orientation of an animal going towards the light as due, not to forced reflexes, but to a more or less voluntary effort to retain a maximum of stimulation. If a creature has reached that plane of psychic development at which it acquires a capacity of reacting with increasing readiness to stimuli which produce an agreeable effect, and of discontinuing those reactions which give rise to unpleasant results, it seems probable that it would not stupidly continue to orient its body and go towards the light if this were not associated with some sort of gratification. If the organism be capable of profiting by experience, we should expect such meaningless behavior sooner or later to be stamped out.

The impulses which are concerned in the reactions of Ranatra to light pass through the principal centers of the nervous system. The responses of the creature to light, if we consider them as reflex acts, cannot, therefore, be reflexes of a very simple kind. The impulses involved must pass from the eye to the brain, thence through the sub-oesophageal ganglion and the ganglia of the ventral nerve cord to the nerves supplying the legs. There are several links in the chain of neurons between the reception and the discharge of the stimulus, and there is abundant opportunity afforded for modification of the reaction through impulses coming from associated parts of the nervous system. As a matter of fact, we have found that the light reactions of Ranatra are modified in this way, as well as conditioned by the general nervous state of the animal. And 
whatever changes in the nervous system may be due to the formation of associations or the effect of habit afford a further element in determining the nature of the phototactic response.

Now, while the light reactions of Ranatra take place to a large degree in a stereotyped and mechanical way, there is much to indicate that the insect seeks stimulation by light much as a bit of food or other object of interest is sought by a higher animal. A dog seeing a piece of meat on the other side of a fence makes a variety of efforts to get the prize. He runs up and down looking for a hole where he can get through or perhaps a low place where he can jump over. We cannot class his actions as direct reflexes in response to outer stimuli. His conduct is determined by the effort to secure a gratifying experience and various methods are employed to gain that end. A Ranatra seeking the light is much less resourceful than a dog trying to get on the other side of a fence, but, to a certain extent, the behavior of both animals is determined by interest in the object sought. As we have seen, Ranatra is able to go towards the light despite obstacles of various kinds. Even when one eye is totally blackened over and all but a small part of the posterior surface of the other is covered, many Ranatras are able to go towards the light in nearly a straight line. How is this done? A Ranatra in this condition is in much the same situation a man would be if one eye were blindfolded and he were attempting to reach a light by walking backwards. A man would accomplish this, if he had not previously seen where the light was situated, in a very indirect manner. By moving his head from side to side he could determine the darkest part of his visual field, and by facing in that direction he would finally be brought by walking backwards to the light. The darkest part of the visual field in this case is a rather indefinite thing as anyone may readily assure himself by trying the exexperiment. A man's course towards the light would probably be very indirect, and it is not a little remarkable that so benighted a creature as Ranatra can reach the goal by so direct a course.

The two sides of the compound eyes must function differ- 


\section{$34^{2}$ Journal of Comparative Neurology and Psychology.}

ently in one respect, since in going towards the light the anterior side is turned so as to face the brightest part of the field of vision while the posterior surface of the eye is kept facing the darkest part. The impulses from the two sides of the eyes do not antagonize each other. The experiments of blackening over the anterior sides of the eyes show that the sides looking away from the light, as well as those looking towards it, play a part in orientation, although they must respond, so tar as seeking intensity of stimulus is concerned, in opposite ways.

The method of trial and error plays, I think, only a subordinate role in the phototaxis of Ranatra, although in some situations it undoubtedly comes into play. There is a certain amount of random movement in the behavior of this form, but deviations from the direct path to the light are usually corrected by an appropriate turn, and not by making a lot of trial movements and following up the successful ones. Ranatras often show periods of hesitation between two directions of turning. Specimens that perform circus movements when one eye is blackened over usually manifest a decided hesitancy when they have turned so that the normal eye looks approximately away from the light. They often stop in their course, turn this way and that, often many times, and occasionally settle down to rest, as if in despair over the situation. Sometimes they turn directly towards the blind side and go to the light; at other times they reach the light only after performing a complete circus movement to the left. When past the critical point their movements usually take place with little hesitation.

Specimens with only the posterior half of one eye exposed often turn slightly this way and that during the first part of their course, as if attempting to get their bearing. If they deviate either to the one side or the other they frequently stop, as if they perceived something to be wrong, turn back and forth several times, and then proceed nearly straight towards the light. In nearly all specimens thus treated one can detect a tendency to veer over towards the normal side, but there are equally obvious efforts to check deviations that are made from the direct path. There is an uneasiness which appears much like impa- 
tience when a Ranatra that shows a strong positive reaction has deviated considerably from a straight path towards the light. When the normal eye looks away from the light the specimen may sway from side to side, back off, then go ahead again, growing continually more excited until finally it takes to flight. If the wings are fastened down to prevent their being used, the insect frequently spends several minutes before getting out of its dilemma. Sooner or later a fortunate movement is made which brings the creature into a situation such that the tendency to turn to a particular side meets with little opposition. Out of many trials made in this state of perplexity a successful one is finally made and followed up. Individuals vary greatly in their conduct in such a situation. Many correct their course before getting far out of orientation; others, when they get out of line, turn back again with comparative readiness.

We might explain the function of the posterior side of the eye in orientation on the supposition that a movement which brightens the visual field brings about a reflex that causes a turn in the opposite direction. In this way deviations from the position that kept the darkest part of the field of vision in focus would be checked and the insect would, therefore, travel towards the light. It is more difficult, however, to explain the orientation of an insect in which a small area of the lateral surface of one eye is the only part exposed. If the insect moved so that the eye would look toward the darkest part of the visual field it would place its body with the blind side towards the light. If, on the other hand, it moved so that the eye would receive the maximum amount of stimulus, the opposite side would be brought toward the light. It is obvious that the insect moves so that the eye receives neither the maximum nor the minimum amount of stimulus, but is kept exposed to light of an intermediate degree of intensity, The degree of intensity varies, moreover, in every step of its course, so that there is no justification for explaining the orientation of the insect through the effort to keep a certain intensity of light constantly before the eye. It is remarkable that Ranatras so treated frequently go towards the light in nearly a straight line. Moreover, if the light is moved 


\section{Journal of Comparative Neurology and Psychology.}

during their progress they change their direction of locomotion so as to continue going towards it. If the light is not carried too far to one side the insect may be made to follow it around in either direction. In the specimens employed care was taken that every other part of the eyes was thickly covered except a small portion of the surface of one side, so there is no doubt that the movements of the insect were directed only by light entering at this point. The side of the eye in this case doubtless functions as it does in a normal individual, but it is difficult to explain satisfactorily the orientation of the specimen either through direct reflexes, or by the method of trial and error. Were the insect so constituted as to respond to an increase of light entering the left eye by a turn to the left and to a decrease of light by a turn to the right, we can understand how, when once pointed towards the light, a straight course might be preserved. If the insect turned towards the right there would be an increase of light entering the left eye which we might suppose stimulates the insect to turn in the opposite direcrion. Deviations to the left would cause a diminution of light entering the left eye, which we might suppose acts as a stimulus to turn to the right side. The right cye may be supposed to act, $m u$ tatis mutandis, in a similar manner. The numerous cases of reaction to shadows (Scattenempfindlichkeit) which are found among several groups of animals show that diminution in the intensity of light may act as a stimulus as well as an increase in intensity. If it be the variations in the intensity of light which afford the stimuli for turning in the one or the other direction, we can attribute to all parts of the eye essentially the same function. If the posterior side of the left eye is all that is exposed and a Ranatra that is facing the light turns to the right side the exposed part of the eye receives an increased stimulus which we may suppose brings about a turn to the left. A turn to the left of the median position, up to a certain point, would probably (owing to the body intercepting a part of the rays) diminish the light entering the posterior side of the eye, thus causing a turn to the right, In this way the creature might be supposed to maintain a straight course towards the light. A 
similar explanation might be applied to the orientation of a Ranatra with only the anterior half, or in fact any other part of the eye exposed. The difficulty with this explanation is that an insect that started with an oblique orientation to the direction of the rays would tend to continue in that position, since a departure from it towards either side would be followed by a compensatory movement. If, however, light produces a constant effect upon the muscular tonus of the body, irrespective of affording stimulation by variations in intensity arising from turning towards different sides, we can better explain the fact of orientation. Take the case of a Ranatra with only the lateral surface of one eye exposed. Light entering the eye tends to increase the action of the flexors on the same side, and that of the extensors on the opposite side of the body. Through this action alone the insect, so far as light directs its movements, would continue to go around in a circle indefinitely. But as a matter of fact, as its circus movements bring the eye away from the light, they become checked and are followed by a turn in the opposite direction. What is the stimulus to this turn? Ob. viously there is a diminution of light received by the eye as it turns away, and we may regard this diminution as a stimulus to a movement in the opposite direction. This stimulus may be conceived, then, to overcome the tendency to the performance of circus movements, and thereby bring about an approximate re-orientation of the creature to the direction of the rays. That there is a conflict of impulses as the insect turns away from the light towards the side with the functional eye is evinced by the hesitancy, the swaying this way and that which often occurs when the creature has reached a position such that the amount of light received by the eye is materially diminished. The effect of light upon the tonus of the muscles of which the behavior of Ranatra gives so much evidence, fails to account for the fact of compensation in the movements of the insect. The responses to variations in the intensity of light, on the other hand, do not adequately account for the preservation of efforts to attain a parallel orientation to the direction of the rays. Each of these factors may, however, supplement the other in such a way as to 


\section{Journal of Comparative Neurology and Psychology.}

cooperate in the maintenance of a direct course towards the light.

But even if we invoke the aid of both the factors mentioned, we are not able completely to bring the phototaxis of Ranatra under the category of direct, mechanical reflexes. Consider the behavior of the Ranatra with its right eye blackened over, placed at right angles to the rays with the normal eye looking away from the light. The effect of light upon the muscular tonus of the creature would tend to make it turn towards the left side. But either at first, or after a few trials, the insect turns directly to the right and goes to the light. This is done with greater readiness after several trials are made; soon the insect turns immediately after being set free. In these experiments the specimens were turned about, first one way and then the other, before being set down on the table, but this made no difference in the directness with which they turned towards the light. In many cases the insects would struggle to turn towards the blind side to get to the light before they were liberated from my hand. So far as could be observed, there was no preliminary feeling about, no employment of the method of trial and error; the insect seemed to retain awareness of the position of the light, since it immediately made for it by the shortest route as soon as it was liberated. The non-mechanical character of the response is further evinced by the fact that habits of turning towards a certain side may be persisted in in situations in which turning would otherwise take place in the opposite direction. The fact that Ranatras and Notonectas which have one eye blackened over come, after several trials, to dispense with circus movements towards the normal side and correct deviations from their course by a direct turn in the right direction affords further evidence for the same conclusion. We have seen that Ranatras which at first will turn only a slight way towards the blinded side when the light is carried over in that direction will make sharper turns after they have become accustomed to following the light around towards that side. These features of the phototaxis of Ranatra indicate that seeking the light has an attractiveness or interest much like that which catching prey has 
for a higher animal. The phototactic movements of the creature are not merely stereotyped reflexes which the insect is involuntarily forced to perform. To get to the light is an end which is arrived at if not by one method, then by another.

The phototaxis of Ranatra comes, to a considerable degree, I believe, under the pleasure-pain type of response. Why a creature should be so constituted as to derive satisfaction from so stupid a performance as wildly chasing after a strong light is a subject that need not concern us in our present quest. The behavior of Ranatra presents the essential features of the pleasure-pain reaction of higher forms, and we are justified, I believe, in classing it under this heading. The fact that Ranatra will continue to follow the light even when it is brought thereby into a situation that produces a fatal effect does not necessarily exclude its conduct from this category. While it is true that animals tend to continue reacting towards stimuli that produce a beneficial effect and away from stimuli that bring about deleterious results, the rule is by no means absolute. In a state of nature Ranatras probably are rarely, if ever, exposed to conditions that produce as strong positive phototaxis as they show under artificial conditions in the laboratory; and there seems to be no benefit that possibly can be derived from their strong propensity to seek the light. This propensity, like that of human beings for certain stimulants and narcotics, has probably not been evolved by natural selection for any useful purpose, but is an incidental result of the way the creature is constituted. Whether there is any connection between pleasure-giving acts which tend to be repeated and acts which secure some benefit to the organism closer than that which would naturally be established through selection may well be doubted. Neither an animal's direct reflexes nor its attempts to seek some source of gratification infallibly lead to securing some benefit; and the fact that a certain kind of behavior is persisted in until it brings about fatal effect does not ipso facto enable us to decide under which of these categories it falls.

It is the apparent telecity in the efforts of Ranatra to reach the light which it is difficult to understand according to a purely 


\section{Journal of Comparative Neurology and Psychology.}

reflex theory of phototaxis. This is a feature of the creature's behavior which, I am inclined to believe, we shall not be able to understand until we can explain the physiology of the process whereby certain stimuli when they have been received one or more times are sought either directly, or indirectly, by a more or less round-about method, while other stimuli when they are experienced one or more times come to be avoided. Did light afford a stimulus of an unpleasant nature, it is probable that the positive phototaxis of Ranatra would soon be inhibited. If the phototaxis of Rantra falls to a certain extent under the category of reflex action, as much in its behavior indicates, the reflexes concerned are in line with a strong instinctive interest of the animal in seeking the light. This interest may lead to successful attempts to get to the light in situations in which purely reflex responses alone would fail. It acts as a sort of regulatory agent in the conduct of the insect, bringing its actions to a successful issue, which could not be attained by a purely machine-like mode of response.

It is through instinctive interests in certain things rather than by simple or even complex reflex acts that the conduct of higher animals is mainly guided. The play activities of higher animals, for instance, are performed, not because they are reflex responses to particular things in the environment, but because the animal is so constituted that it derives satisfaction from their performance. An animal interest may be chained, by virtue of its organization, to certain ends, such as the capture of a certain kind of prey, or the construction of a particular kind of habitation; but at the same time its conduct may show considerable plasticity as regards the methods by which these ends are attained. In instinctive behavior, as in the morphogenic processes which lead to the establishment and maintenance of the normal form of the body there is an apparent effort to reach a certain end result, despite obstacles and unusual conditions. The explanation of this peculiarity of animal behavior is a problem of fundamental interest. If we attempt to resolve highly complex modes of behavior into simple direct reflexes, we soon find ourselves at the end of our tether. Even in so apparently 
mechanical procedure as the phototaxis of Ranatra we encounter peculiarities which indicate that we have not struck bottom in our analysis of the phenomenon.

In many ways the phototaxis of the Ranatra seems to be intermediate between purely reflex conduct on the one hand and conduct of the pleasure-pain type on the other. These two kinds of behavior seem to be harmoniously combined in many instincts, if not in most of the more highly involved modes of instinctive action. Just what the steps are which lead from the one to the other we do not.know. We are still in want of a satisfactory explanation of the pleasure-pain type of response. When we are able to supply one we shall be in a position to give a more adequate interpretation of the phototaxis of higher forms than can be supplied at the present time. 